\title{
Recovery of humic substances from landfill leachate via 2500 Da ultrafiltration membrane
}

\author{
D. Yue, B. Han, G. Qi \& Y. Cheng \\ Key Laboratory for Solid Waste Management and Environment Safety, \\ Ministry of Education of China, Tsinghua University, China
}

\begin{abstract}
Landfill leachate management is getting more and more attention because of its seriously potential environmental impact. Humic substances (HS), which lead to the difficulty of landfill leachate treatment, can also be recovered and used as a fertilizer for soil or remediation agent for contaminated sites. A 2500 Da ultrafiltration membrane was applied to separation of humic substances from salts and heavy metals in landfill leachate in this study. Humic substances recovery ratio was $50-70 \%$. The fractional recovery of HS decreased from up to $100 \%$ to about $55 \%$ as concentration factor (CF) increased from 2 to 6 . Fractional removals of $\mathrm{K}^{+}, \mathrm{Na}^{+}, \mathrm{Mg}^{2+}$, and $\mathrm{Ca}^{2+}$ were up to $85 \%, 85 \%, 89 \%$, and $51 \%$, respectively. Fractional removals of heavy metals were more than $75 \%$, $60 \%$, and $78 \%$, respectively. The 2500 Da UF performed well in separating HS from salts and heavy metals and in concentrating HS.
\end{abstract}

Keywords: landfill leachate, humic substances, ultrafiltration, $2500 \mathrm{Da}$, separation.

\section{Introduction}

Landfill leachate management is getting more and more attention because of its serious pollution to the environment and the treatment difficulties. Landfill leachate always contains a lot of refractory humic substances (HS), which may be simply classified into humic acid (HA) and fulvic acid (FA), and the HS content increases with landfill age [1-3]. The existence of HS affects significantly negatively the efficiency of biological treatment $[4,5]$, which is the predominant treatment process of landfill leachate all over the world. In recent years, advanced biological techniques such as the Membrane Bio-reactor (MBR) 
technique have been widely adopted to treat landfill leachate, but the effluent cannot meet the discharge control criteria. Consequently, the bio-treated leachate usually requires further treatment with nanofiltration (NF) or reverse osmosis (RO) to meet the stringent effluent discharge criteria. This results in very expensive operation costs while generating plenty of retentates which are more refractory due to the enriched HS [6-8].

HS are naturally occurring mixtures of organic compounds that play an important role in both pollutant chemistry and biogeochemistry of natural waters and soils [9]. The chemical composition, structure, and characteristics of HS from landfill solid and leachate have been investigated by many researchers [1012]. Chemical features of HS provide the potential to utilize HS as an agent for fertilization [2] and/or pollution remediation [13]. Separation of HS from landfill leachate can not only recover bio-fertilizer from waste, but also reduce the cost of landfill leachate treatment. Previous research has been conducted to separate and recover HS from leachate via an ultrafiltration (UF) device (1000 Da) [2]. In this paper, the efficiency of $2500 \mathrm{Da}$ UF membrane for separating HS from landfill leachate was investigated.

\section{Materials and methods}

\subsection{UF device for HS recovery}

The HS separation process is shown in Figure 1. Spiral-wound membrane components (MWCO $2500 \mathrm{Da}$ ), purchased from General Electric Co. (Detroit, $\mathrm{MI}$ ), were used in the system. Landfill leachate stored in the stock solution reservoir first flows through the security filter to remove large materials, and

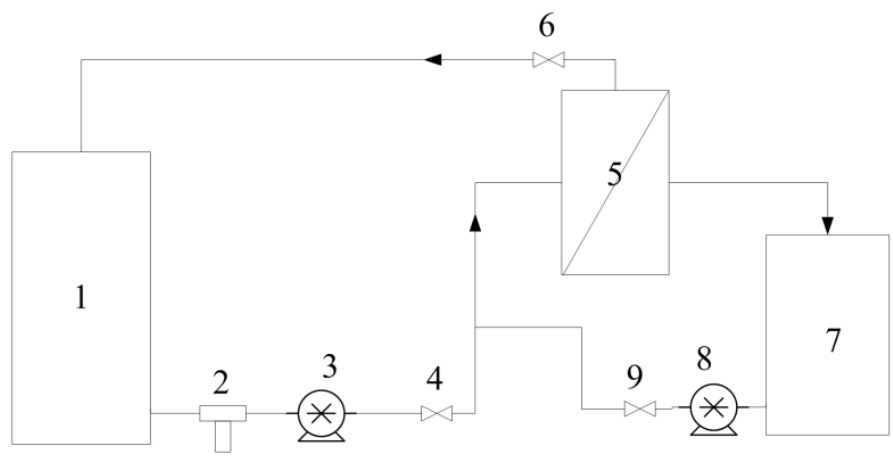

[1] stock solution tank [2] security filter [3] feed pump [4] feed valve

[5] ultrafiltration membrane components [6] exit valve [7] permeate liquid tank

[8] scavenging pump [9] scavenging valve

Figure 1: UF equipment for separating HS from landfill leachate. 
then is pumped into the UF membrane module. After that, the permeate liquid is piped into permeate liquid tank, and the retentate is pumped back to the stock solution reservoir. The equipment was operated continuously until the expected concentration factor $(\mathrm{CF})$, which was defined as the ratio of influent volume to concentrate volume, was achieved.

\subsection{Analytical methods}

The extraction and preparation method of HS was referred to the procedure employed by Christensen et al. [14]. Firstly, hydrochloric acid was added to the leachate samples until reaching a $\mathrm{pH}$ value of 1.0, and then the samples were placed overnight. Secondly, the precipitate in the samples was separated by centrifugation at 4000rpm for 20 minutes. This precipitate corresponded to HA. The concentration of HA was calculated as the difference of DOC between the stock solution and the supernate. Thirdly, having been adjusted to a $\mathrm{pH}$ value 2.0 with $5.0 \mathrm{M} \mathrm{NaOH}$, the supernate was pumped onto a Chromatography Column with Amberlite XAD-8, which can adsorb FA after prior acidification of samples. After that, FA was desorbed with $0.1 \mathrm{M} \mathrm{NaOH}$ washing. Salts and heavy metals were analyzed by ICP-AES (Thermo Electron Co.).

\section{Results and discussion}

\subsection{Concentration of HS}

Figure 2 shows the variation of HS purity with separation pressure and CF. The purity of $\mathrm{HS}$ in concentration solution varies little with $\mathrm{CF}$. When the pressure was between $0.7 \mathrm{MPa}$ and $1.1 \mathrm{MPa}$, the purity of $\mathrm{HS}$ was about $10 \%$ higher than the feed $(40 \%)$, while it was about $30 \%$ higher under $1.2 \mathrm{MPa}$, probably resulting from the ease at which low molecular weight organics can pass through UF membrane with a high pressure.

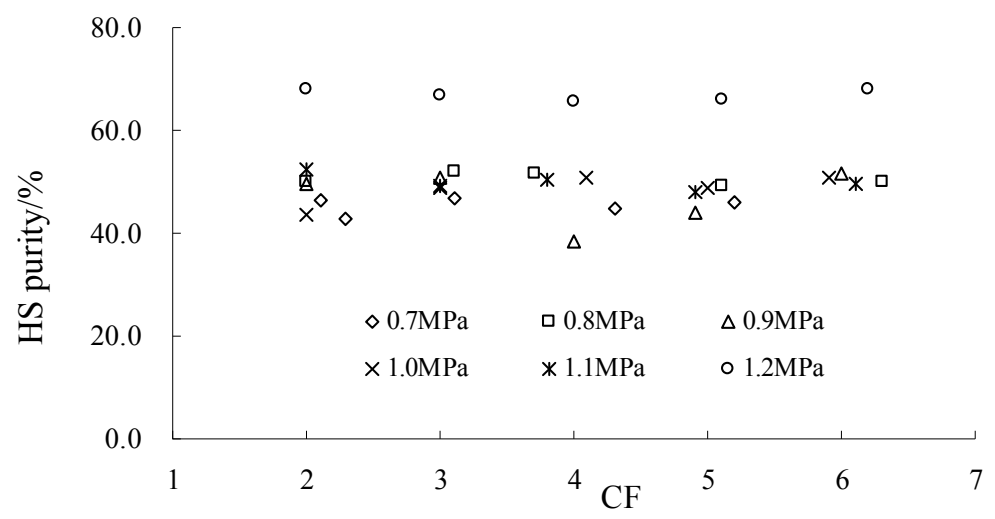

Figure 2: Variation of HS purity. 
It is believed that HS has various molecular weights. Smaller ones enter the permeate driven by the pressure. Figure 3 shows the fractional recovery of HS with pressure and CF. With the lower CF (2-4), the fractional recovery of HS under low pressure was higher than that under high pressure, and the trend was reverse under the higher CF (4-6). When CF increased from 2 to 6 , the fractional recovery of HS decreased from up to $100 \%$ to about $55 \%$. The change of fractional recovery of HS varied with pressure. Under $0.7 \mathrm{MPa}-0.9 \mathrm{MPa}$, the droop rate of the fractional recovery of HS increased as the pressure increased, while under 1.0-1.1 MPa, the droop rate of the fractional recovery of HS decreased.

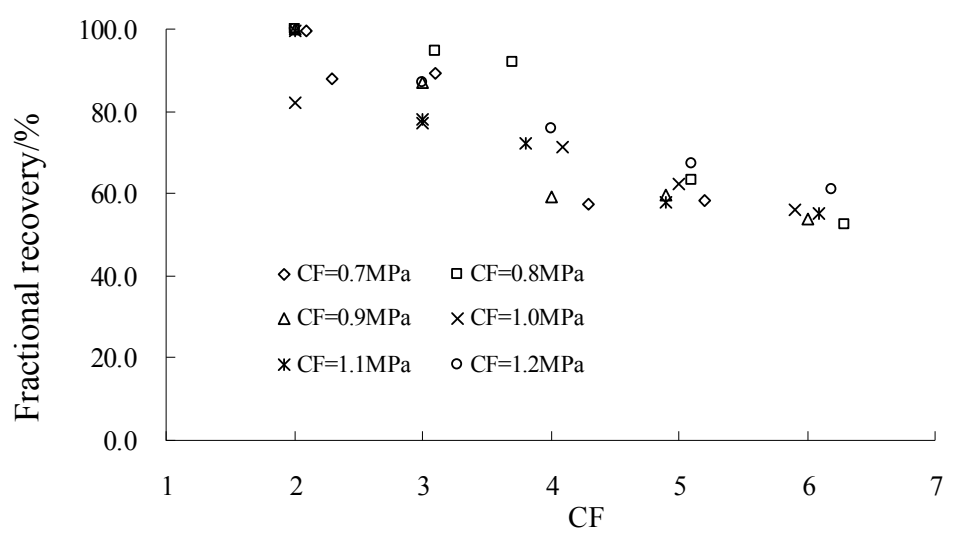

Figure 3: Fractional recovery of HS.

\subsection{Removal of inorganic salts}

Figures 4 and 5 show the fractional removal of $\mathrm{K}^{+}$and $\mathrm{Na}^{+}$under different pressure. The UF used in experiment could remove $\mathrm{K}^{+}$and $\mathrm{Na}^{+}$effectively. With

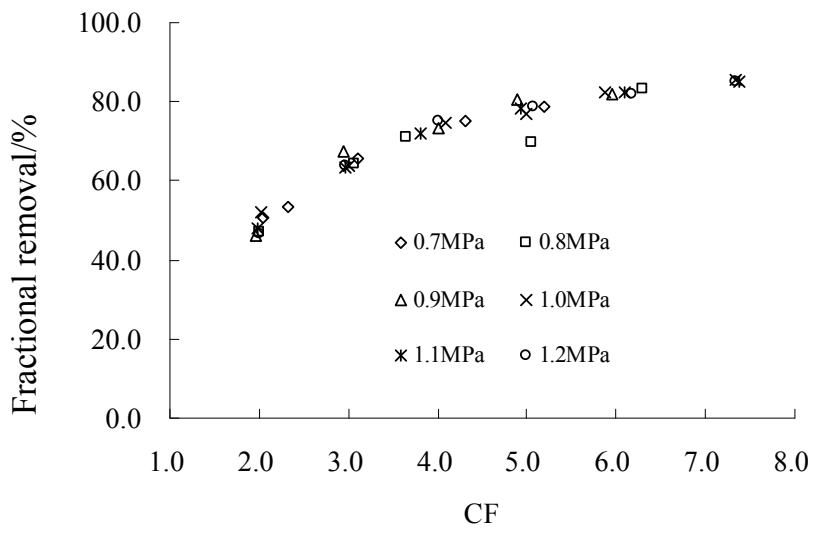

Figure 4: $\quad$ Fractional removal of $\mathrm{K}^{+}$. 


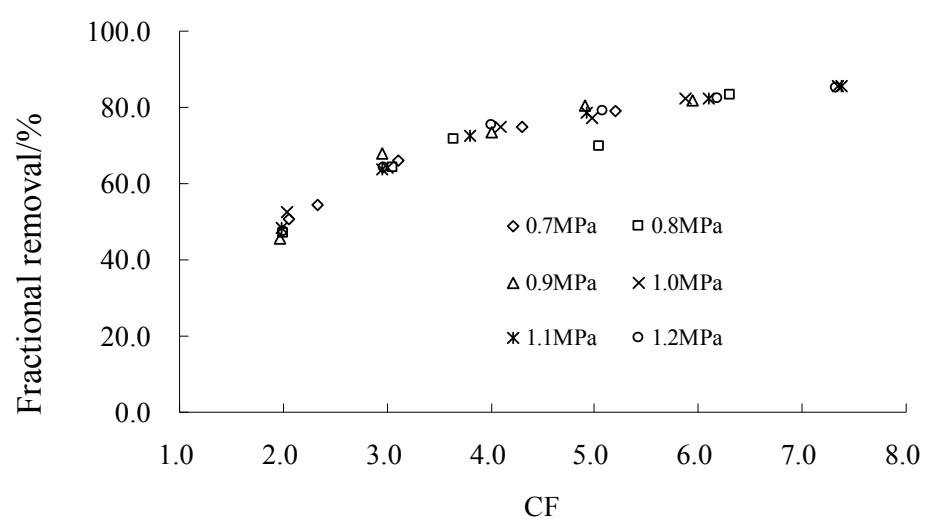

Figure 5: Fractional removal of $\mathrm{Na}^{+}$.

the increase of $\mathrm{CF}$, the fractional removal could be divided into two stages. When CF was between 2 and 4, the fractional removals of $\mathrm{K}^{+}$and $\mathrm{Na}^{+}$increased dramatically from $45 \%$ to $75 \%$, while $\mathrm{CF}$ was bigger than 5 , they increased slowly from $78 \%$ to $85 \%$.

Figures 6 and 7 show the fractional removal of $\mathrm{Ca}^{2+}$ and $\mathrm{Mg}^{2+}$ with pressure and CF. The fractional removal of $\mathrm{Ca}^{2+}$ and $\mathrm{Mg}^{2+}$ were lower than that of $\mathrm{K}^{+}$and $\mathrm{Na}^{+}$. With the increase of $\mathrm{CF}$, the fractional removal increased from $16 \%$ to $37 \%-51 \%$ for $\mathrm{Ca}^{2+}$, from $44 \%$ to $83 \%-89 \%(\mathrm{CF} \geq 5)$ for $\mathrm{Mg}^{2+}$. The distinguished difference between the fractional removal of $\mathrm{Ca}^{2+}$ and $\mathrm{Mg}^{2+}$ was because of the huge amount of carbonate $(2000 \mathrm{mg} / \mathrm{L}-3000 \mathrm{mg} / \mathrm{L})$ combine with $\mathrm{Ca}^{2+}$ into precipitated $\mathrm{CaCO}_{3}$ under the basic circumstance $(\mathrm{pH}=8)$, thereby decreasing the fractional removal of $\mathrm{Ca}^{2+}$.

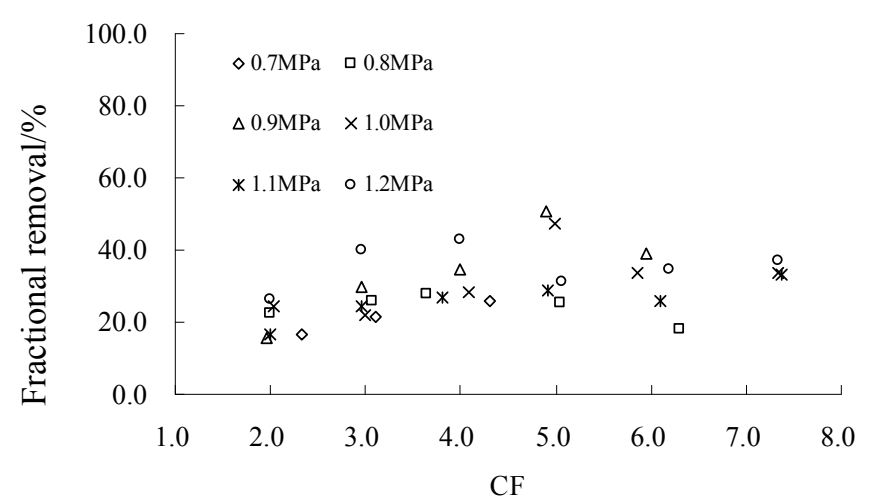

Figure 6: Fractional removal of $\mathrm{Ca}^{2+}$. 


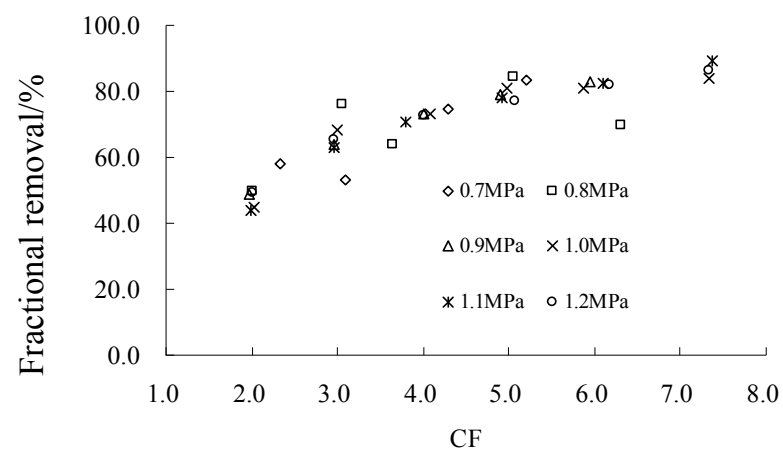

Figure 7: Fractional removal of $\mathrm{Mg}^{2+}$.

Figure 8 shows the fractional removal of $\mathrm{Fe}^{2+}$ with pressure and CF. Different from the inorganic salts mentioned above, the fractional removal of $\mathrm{Fe}^{2+}$ was $5.8 \%$ to $14.5 \%$. . It was possible that the $\mathrm{Fe}^{2+}$ combined with some of the organic matter in the leachate and was being intercepted in the concentrate mostly.

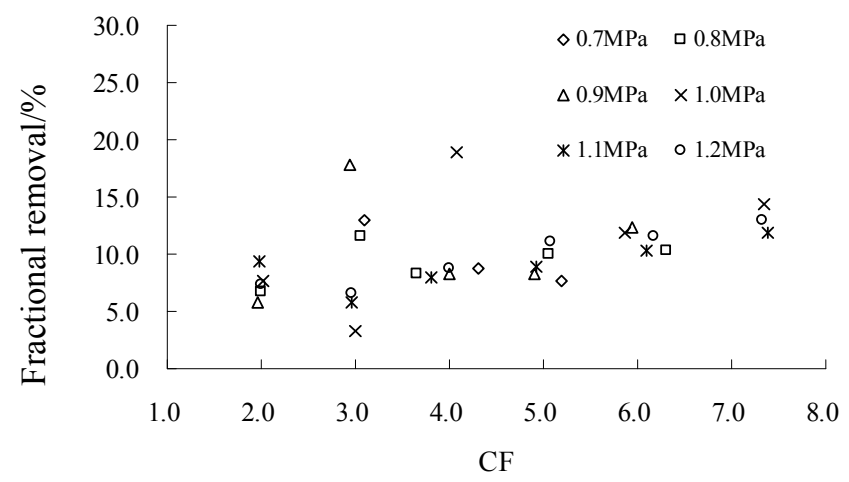

Figure 8: Fractional removal of $\mathrm{Fe}^{2+}$.

The 2500 Da UF performed well in removing $\mathrm{K}^{+}, \mathrm{Na}^{+}, \mathrm{Mg}^{2+}$ with $\mathrm{CF}$ between 5 and 7. The lower fractional removal of $\mathrm{Ca}$ might be because of the precipitation of $\mathrm{CaCO}_{3}$. The operation pressure had little impact on the removal of inorganic salt irons. The $\mathrm{Fe}^{2+}$ combined with some of the organic matter in the leachate and was intercepted in the concentrate.

\subsection{Removal of heavy metals}

In the leachate there were heavy metals such like $\mathrm{Zn}, \mathrm{Ba}, \mathrm{Mn}, \mathrm{Cu}, \mathrm{Cr}, \mathrm{Pb}$, As and $\mathrm{Ni}$, whose concentrations are shown in table 1 . The removal of heavy metal by UF was investigated. 
Table 1: $\quad$ Concentrations of heavy metals in leachate $(\mathrm{mg} / \mathrm{L})$.

\begin{tabular}{cccc}
\hline Item & Value & Item & Value \\
\hline $\mathrm{Zn}$ & 1.00 & $\mathrm{~Pb}$ & 0.23 \\
$\mathrm{Ba}$ & 1.21 & $\mathrm{As}$ & 4.08 \\
$\mathrm{Mn}$ & 0.52 & $\mathrm{Ni}$ & 0.10 \\
$\mathrm{Cu}$ & 0.16 & $\mathrm{Cr}$ & 0.17 \\
\hline
\end{tabular}

Results showed that $\mathrm{Cu}, \mathrm{Cr}$ and $\mathrm{Ni}$ cannot be removed from the leachate because they have strong ability to coordinate with HS. Figures 9 and 10 are the fractional removal of $\mathrm{Ba}$ and $\mathrm{Mn}$ with pressure and $\mathrm{CF}$. Pressure did not impact the fractional removal very much. Their fractional removals increased with the

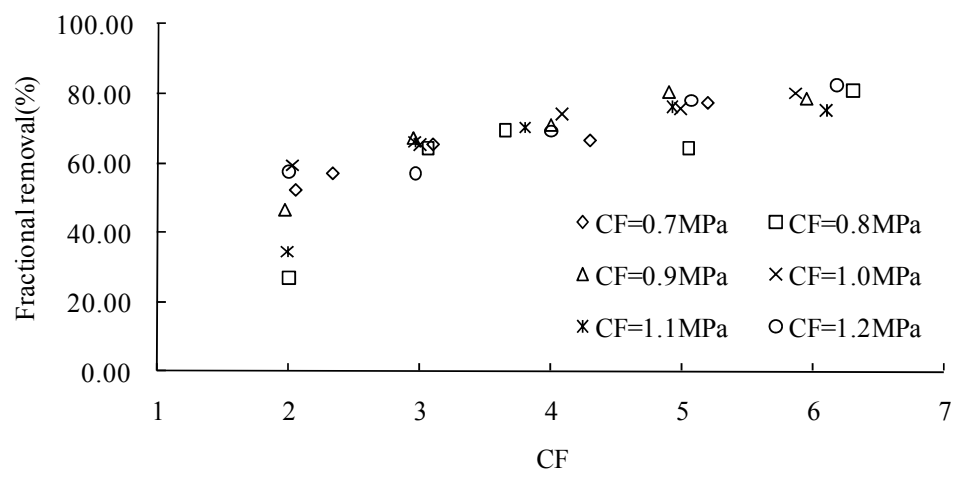

Figure 9: Fractional removal of $\mathrm{Ba}$.

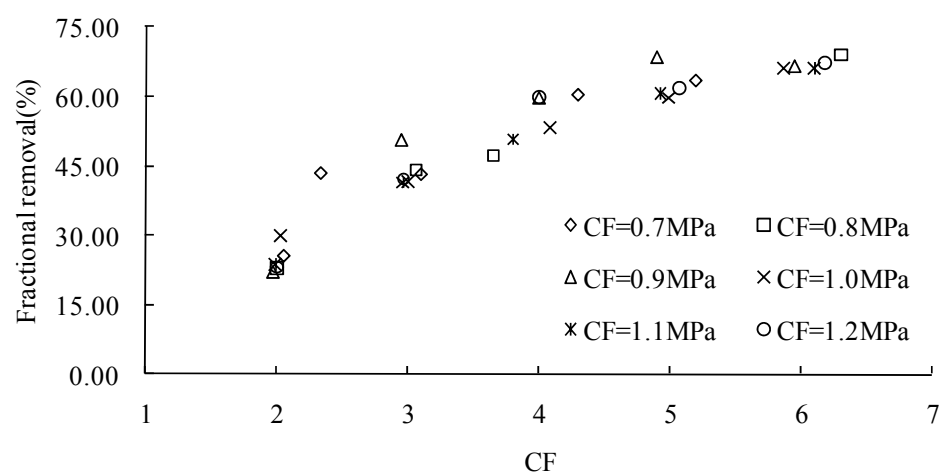

Figure 10: Fractional removal of $\mathrm{Mn}$. 
$\mathrm{CF}$. When $\mathrm{CF}$ was larger than 5, the fractional removal of $\mathrm{Ba}$ and $\mathrm{Mn}$ were more than $75 \%$ and $60 \%$, respectively. The UF can remove Ba and Mn well.

Figure 11 shows the fractional removal of As with pressure and CF. The fractional removal increased with the $\mathrm{CF}$. The fractional removal was larger in high pressure $(1.0,1.1,1.2 \mathrm{MPa})$ than that in low pressure $(0.7,0.8,0.9 \mathrm{MPa})$. With the increasing $\mathrm{CF}$, the gap between fractional removals under high and low pressure decreased. When $\mathrm{CF}$ was 5 , the fractional removals were almost the same and more than $78 \%$.

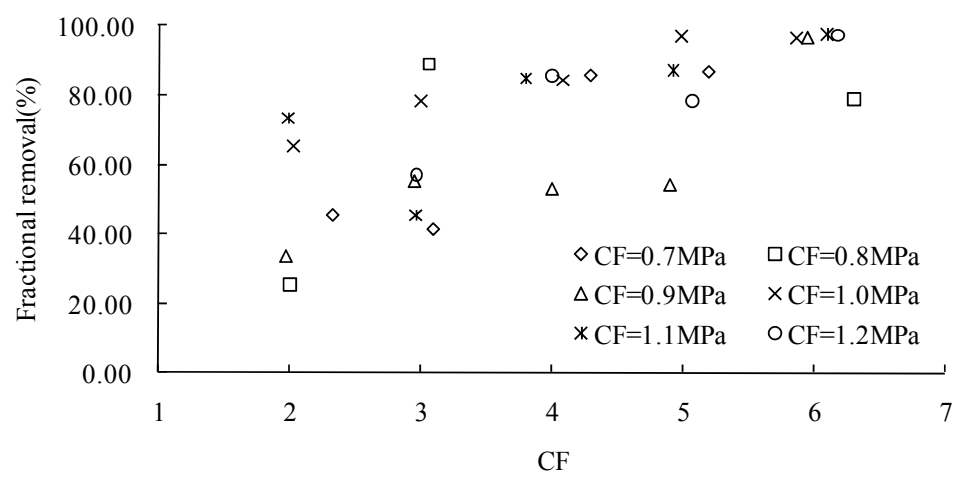

Figure 11: Fractional removal of As.

Figures 12 and 13 are the fractional removal of $\mathrm{Zn}$ and $\mathrm{Pb}$ with pressure and $\mathrm{CF}$. Under all pressure conditions, the fractional removal of $\mathrm{Zn}$ increased with $\mathrm{CF}$. $\mathrm{Pb}$ followed the similar rules with $\mathrm{Zn}$ expect that under $0.7 \mathrm{MPa}$ the fractional removal of $\mathrm{Pb}$ decreased before it increased. Pressure did not impact fractional removal apparently. When $\mathrm{CF}$ was larger than 5, the fractional removal of $\mathrm{Zn}$ was higher than $50 \%$, while that of $\mathrm{Pb}$ was higher than $60 \%$.

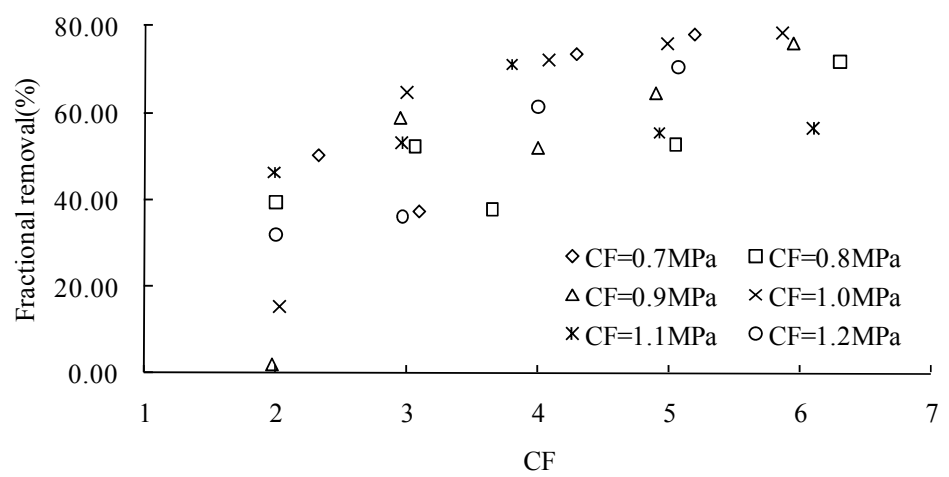

Figure 12: Fractional removal of $\mathrm{Zn}$. 


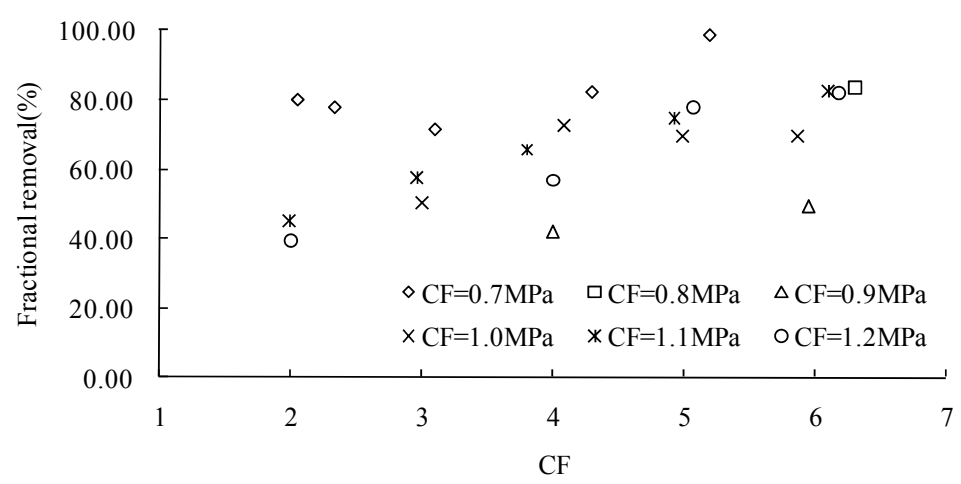

Figure 13: Fractional removal of $\mathrm{Pb}$.

\section{Conclusions}

A 2500 Da UF was applied to separate HS from salts and heavy metals in landfill leachate. The purity of HS was about $50 \%$ when the pressure was between 0.7 $\mathrm{MPa}$ and $1.1 \mathrm{MPa}$ and about $70 \%$ when the pressure was $1.2 \mathrm{MPa}$. The fractional recovery of $\mathrm{HS}$ decreased from up to $100 \%$ to about $55 \%$ as $\mathrm{CF}$ increased from 2 to 6. Fractional removals of $\mathrm{K}^{+}, \mathrm{Na}^{+}, \mathrm{Mg}^{2+}$, and $\mathrm{Ca}^{2+}$ were up to $85 \%, 85 \%, 89 \%$, and $51 \%$, respectively. Fractional removals of heavy metals were more than $75 \%, 60 \%$, and $78 \%$, respectively. The 2500 Da UF performed well in separating HS from salts and heavy metals and in concentrating HS.

\section{Acknowledgements}

This work was supported by the National Key Project of Scientific and Technical Supporting Programs of China (NO. 2006BAC06B05 \& NO. 2006BAC06B01), the Beijing Science and Technology Project (D08040600350804) and the Key Laboratory for Solid Waste Management and Environment Safety, Ministry of Education of China (No. SWMES2010-12).

\section{References}

[1] Chian, E.S.K., 1977. Stability of organic matter in landfill leachate. Water Res. 11, 225-232.

[2] Xu, Y., Yue, D., Zhu, Y., Nie, Y., 2006. Fractionation of dissolved organic matter in mature landfill leachate and its recycling by ultrafiltration and evaporation combined processes. Chemosphere 64, 903-911.

[3] Kurniawan, T.A., Lo, W., 2009. Removal of refractory compounds from stabilized landfill leachate using an integrated $\mathrm{H} 2 \mathrm{O} 2$ oxidation and granular activated carbon (GAC) adsorption treatment. Water Res. 43, 4079-4091. 
[4] Chiang, L.C., Chang, J.E., Chung, C.T., 2001. Electrochemical oxidation combined with physical-chemical pretreatment processes for the treatment of refractory landfill leachate. Environmental Engineering Science 18, 369-379

[5] Rodriguez, J., Castrillon, L., Maranon, E., Sastre, H., Fernandez. E., 2004. Removal of non-biodegradable organic matter from landfill leachates by adsorption. Water Res. 38, 3297-3303.

[6] Robinson, T. Membrane bioreactors: Nanotechnology improves landfill leachate quality. Filt. Separat. 2007, 44, 38-39.

[7] Alvarez-Vazquez, H; Jefferson, B.; Judd, S.J. Membrane Bioreactors vs Conventional Biological Treatment of Landfill Leachate: A Brief Review. J. Chem. Technol. Biot. 2004, 79, 1043-1049.

[8] Ahn, W.Y.; Kang, M.S.; Yim, S.K.; et al. Advanced Landfill Leachate Treatment Using An Integrated Membrane Process. Desalination. 2002, $149,109-114$.

[9] Aiken, G.R.; McKnight, D.M.; Warshaw, R.L.; et al. An introduction to humic substances in soil, sediment, and water. In: Aiken GR, McKnight DM, Warshaw RL, editors. Humic substances in soil, sediment, and water. New York: Wiley, 1985, 1-9.

[10] Chiou, C.T.; Kile, D.E.; Brinton, T.I.; et al. A Comparison of Water Solubility Enhancements of Organic Solutes by Aquatic Humic Materials and Commercial Humic Acids. Environ. Sci. Technol. 1987, 21, 1231-1234.

[11] Castagnoli, O.; Musmeci, L.; Zavattiero, E.; et al. Humic Substances and Humification Rate in A Municipal Refuse Disposed of in A Landfill. Water Air Soil Pollut. 1990, 53, 1-12.

[12] Nanny, M.A.; Ratasuk, N. Characterization and Comparison of Hydrophobic Neutral and Hydrophobic Acid Dissolved Organic Carbon Isolated From Three Municipal Landfill Leachate. Water Res. 2002, 36, $1572-1584$.

[13] Kang, K.H.; Shin, H.S.; Park, H. Characterization of Humic Substances Present in Landfill Leachate with Different Landfill Ages and its implications. Water Res. 2002, 36, 4023-4032

[14] Christensen, J.B; Jensen, D.L.; Gron, C.; et al. Characterization of the Dissolved Organic Carbon in Landfill Leachate-polluted Groundwater. Water Res. 1998, 32, 125-135 